\title{
Transcatheter mitral valve intervention: Consensus, quality, and equipoise
}

Vinay Badhwar, MD

Commencing in 2020 and for the next 5 years, transcatheter mitral valve (MV) intervention will see investigational device applications develop into approved therapies for clinical practice. This will move the field from one that treats only primary mitral regurgitation (MR) of prohibitive surgical risk to one with expanding access to transcatheter MV repair (TMVr) or replacement (TMVR) options for patients with secondary or mixed MR and, eventually, for patients deemed to be at high or perhaps even intermediate risk.

The American Association for Thoracic Surgery, American College of Cardiology (ACC), Society for Cardiovascular Angiography and Interventions, and Society for Thoracic Surgeons (STS) have collaborated to provide recommendations for institutions and individual operators for commencing and maintaining a comprehensive multidisciplinary transcatheter MV intervention program. ${ }^{1}$ Simultaneously, a similar multi-stakeholder ACC expert consensus has been updated to incorporate current diagnosis and treatment algorithms for primary, secondary, and mixed MR. ${ }^{2}$ As access to TMVr and TMVR therapies becomes available to treat more than primary MR, it will be imperative to maintain and pursue quality outcomes focused on short-term and longitudinal benefit. As equipoise between surgical and transcatheter therapy is likely to continue for the foreseeable future, the American Association for Thoracic Surgery, ACC, Society for Cardiovascular Angiography and Interventions, and STS are united in the belief that adherence to consensus recommendations will maximize the successful introduction of these options into evidence-based clinical pathways of care.

The objective of the following review is to assist in summarizing the momentum behind transcatheter and minimally invasive MV therapy in an effort to prepare operators for a future when patients may have access to conventional mitral valve repair or replacement (MVRR), minimal

\footnotetext{
From the Department of Cardiovascular and Thoracic Surgery, West Virginia University, Morgantown, WVa.

Received for publication Feb 11, 2020; revisions received March 1, 2020; accepted for publication March 4, 2020; available ahead of print May 8, 2020.

Address for reprints: Vinay Badhwar, MD, Department of Cardiovascular and Thoracic Surgery, West Virginia University, 1 Medical Center Drive, Morgantown, WV 26506 (E-mail: vinay.badhwar@wvumedicine.org).

J Thorac Cardiovasc Surg 2020;160:93-8 0022-5223/\$36.00

Copyright (c) 2020 Published by Elsevier Inc. on behalf of The American Association for Thoracic Surgery

https://doi.org/10.1016/j.jtcvs.2020.03.059
}

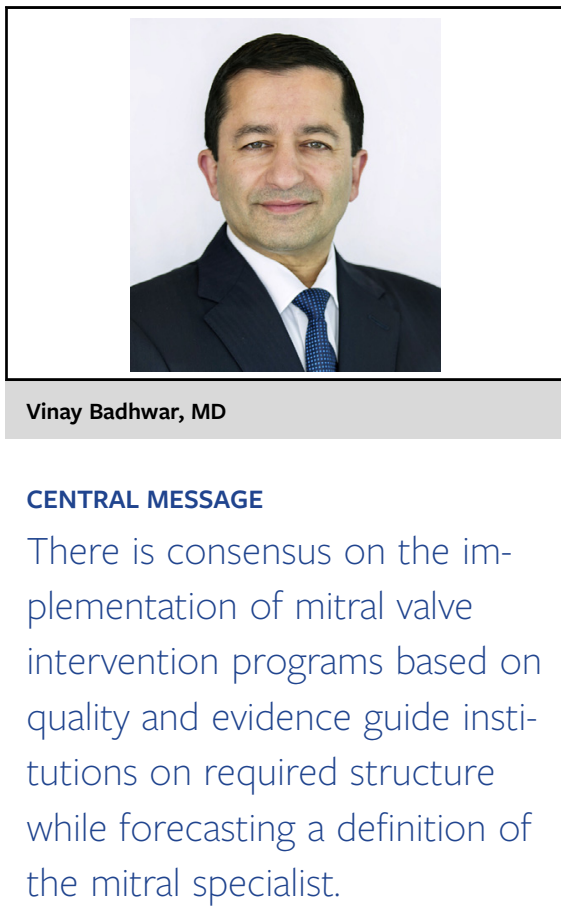

This Invited Expert Opinion provides a perspective on the following paper: JTCVS. 2019;160. https://doi.org/10.1016/j.jtcvs.2019.12.001.

See Commentaries on pages 99 and 100.

access or robotic MVRR, or transcatheter MVRR facilitated by several devices for an array of pathologies. The detailed understanding of these elements and their application with longitudinal quality outcomes will define the future mitral specialist.

\section{Institutional and Operator Consensus Recommendations}

Central to the initiation and maintenance of a comprehensive transcatheter MV program is a fully functional multidisciplinary heart team (MDT). ${ }^{1}$ An important distinction from traditional transcatheter aortic valve replacement structural heart teams is recommended in both composition and focus toward the goal of helping secure shared decision making of complex MV management options. The MDT should be co-directed by an interventional cardiologist and MV surgeon, and be composed of at least 1 imaging specialist (quantitative echocardiography, cardiac 
computed tomography, and magnetic resonance imaging), general valvular heart disease cardiologist, and heart failure cardiologist who may work in conjunction with an electrophysiologist to adjudicate guideline-directed medical therapy (GDMT) that may include resynchronization when indicated. ${ }^{1,2}$ In addition to supportive allied health and nursing providers, additional team members might include cardiac anesthesia and cardiac critical care. As institutions are required to report to both the STS Adult Cardiac Surgery Database and the STS/ACC Transcatheter Valve Therapies Registry, quarterly MDT data quality meetings are recommended to equally review outcomes of both transcatheter and surgical MV intervention. As TMVr and TMVR therapies for both primary and secondary MR are introduced to a population with increased complexity and comorbidities, the following institutional commitments are necessary: (1) dedication to the nonreimbursable activities of the MDT; (2) access to hybrid fixed-imaging suites with operating room sterility and cardiac anesthesia standards; (3) intraprocedural 3-dimensional transesophageal echocardiography (TEE); (4) availability of cardiopulmonary bypass support; and (5) access to postprocedural specialized cardiac critical care.

As of this writing, the edge-to-edge clip device MitraClip (Abbott, Santa Clara, Calif) is the only transcatheter MV intervention system approved by the US Food and Drug Administration. This is most often deployed by a single operator, which may be an interventional cardiologist or MV surgeon, although the complementary expertise of 2 operators (ie, MV surgeon and interventional cardiologist) may be required in some cases. The future delivery of novel transcatheter MVRR systems are likely to receive a joint operator recommendation of both a surgeon and an interventional cardiologist. ${ }^{1}$

Consensus recommendations ${ }^{1}$ for $\mathrm{MV}$ intervention programs were not intended to exclude existing or future centers but instead to focus on the goals of improving data-driven access and quality across all sites that follow appropriate use criteria and case selection. These recommendations are summarized in Table 1. Surgical requirements to initiate a transcatheter MV intervention program are institutional site volumes of at least 40 annual MV operations or 80 over 2 years with at least half being MV repairs and a minimum of 2 surgeons to facilitate both participation in MDT and MV management and simultaneous ability to attend to necessary urgent care.

Implementation of consensus recommendations ${ }^{1}$ will enable programs to offer a spectrum of MV interventions for primary MR and secondary MR while ensuring resource availability to adequately manage patient complexities and accompanying comorbidities.

\section{Therapy for Primary Mitral Regurgitation}

Surgical MV repair provides durable reduction of primary MR that is superior to current edge-to-edge transcatheter options. $^{3-7}$ The edge-to-edge clip is currently approved in the United States for patients with primary MR deemed to be prohibitive risk for surgical therapy. To date, there have been more than 100,000 patients treated worldwide (ref: Abbott). Guided by interventional echocardiography, often with 3-dimensional imaging, this transvenous steerable device is delivered by a trans-septal approach to grasp the anterior and posterior leaflets simultaneously at the primary lesion to provide MR reduction. For teams and operators (MV surgeon or interventional cardiologist) experienced in procedural identification of the precise lesion and mechanism of MR, then steering the device in place for precise leaflet grasping, it can be a straightforward and efficient procedure. However, if any of these elements are off, hazards may be encountered that may jeopardize the safety and efficacy of the procedure. For example, if the imaging is neither clear nor delivered by an experienced interventional echocardiographer, who knows each step of the procedure from trans-septal puncture to leaflet grasping, pitfalls of incomplete elimination of MR, or worse may result. ${ }^{8}$ If the operators are facile with the device but do not fully understand the mechanism of MR, it may result in ineffective MR reduction. ${ }^{5,6}$ This is particularly important when there may be a mechanism involving mixed restriction or when lesions are not exactly at the A2-P2 location. The role of the comprehensive MV MDT is to prepare for the procedure in advance to mitigate these scenarios while planning the selection of type of MitraClip to optimally treat the lesion: short grasping arms (NTR) versus long grasping arms (XTR). The experienced MV surgeon is often particularly valuable in assisting with interpretation of the MR mechanism and predicting lesion therapy based on TEE. Preoperative anatomic predictions of lesion location and mechanism, factored in with annular size, calcium, and gradients, coalesce into the determination by the MDT if the patient is clipable. Preprocedural assessment of effective clipability and MR reduction without resultant stenosis is an important primary function of an experienced MDT to responsibly direct patient safety, resource use, and appropriate use. Therefore, it is not surprising that a significant volume-outcome association appears to exist for $\mathrm{TMVr}^{9}$ and why consensus recommendations focus on multidisciplinary procedural expertise of surgeons, imagers, and interventional cardiologists to have an effective MV intervention program. ${ }^{1,2}$

Institutions without an experienced MV surgical program may struggle to determine the best path of therapy for patients with primary MR at higher, but not prohibitive, comorbid risk. ${ }^{10}$ Patients in whom clinical reasons may 
TABLE 1. Consensus recommendations for new and established transcatheter mitral valve programs

\begin{tabular}{|c|c|c|}
\hline Criteria & New MV intervention programs & Established MV intervention programs \\
\hline \multicolumn{3}{|l|}{ Volume } \\
\hline PCI & $\geq 300$ per year & $\geq 300$ per year \\
\hline MV surgery & $\begin{array}{l}\text { - } \geq 40 \mathrm{MV} \text { operations per year or } 80 \text { over } 2 \text { y } \\
\text { (at least } 50 \% \text { MV repairs) } \\
\text { - One MV surgeon with } 20 \mathrm{MV} \text { operations per } \\
\text { year or } 40 \text { over } 2 \text { y (at least } 50 \% \text { MV repairs) } \\
\text { - Minimum of } 2 \text { surgeons }\end{array}$ & $>20$ cases per year or $>40$ cases over prior 2 y \\
\hline MV intervention & $\begin{array}{l}\text { - Certification of Device Training } \\
\text { - Minimum Operator* Requirements of } 50 \text { lifetime } \\
\text { structural heart procedures, } 20 \text { lifetime trans-septal } \\
\text { interventions, and TMVr experience of } 10 \\
\text { procedures as primary or coprimary }\end{array}$ & $\begin{array}{l}>20 \text { transcatheter MV interventions per year } \\
\quad \text { or }>40 \text { over prior } 2 y\end{array}$ \\
\hline \multicolumn{3}{|l|}{ Quality } \\
\hline PCI Outcomes & $\begin{array}{l}\text { In-hospital risk-adjusted mortality greater than } \\
\text { lowest } 25 \text { th percentile over } 12 \text { mo }\end{array}$ & $\begin{array}{l}\text { In-hospital risk-adjusted mortality }>\text { lowest } 25 \text { th percentile } \\
\text { over } 12 \text { mo }\end{array}$ \\
\hline Registry Participation & NCDR, STS/ACC TVT, STS ACSD & NCDR, STS/ACC TVT, STS ACSD \\
\hline STS Rating & $\begin{array}{l}\text { As expected or higher for at least } 2 \text { consecutive } \\
\text { performance reporting periods per year for both } \\
\text { MVRR and MVRR plus CABG }\end{array}$ & $\begin{array}{l}\text { As expected or higher for at least } 2 \text { consecutive performance } \\
\text { reporting periods per year for both MVRR and MVRR } \\
\text { plus CABG }\end{array}$ \\
\hline
\end{tabular}

$M V$, Mitral valve; $P C I$, percutaneous coronary intervention; $T M V r$, transcatheter mitral valve repair; NCDR, National Cardiovascular Data Registry; STS/ACC TVT, Society of Thoracic Surgeons American College of Cardiology Transcatheter Valve Therapy; STS ACSD, Society of Thoracic Surgeons Adult Cardiac Surgery Database; CABG, coronary artery bypass grafting; MVRR, mitral valve repair or replacement. *Operator may be an interventional cardiologist or surgeon.

exist for why a sternotomy may not be optimal, such as relative frailty, may be relegated to receive therapy other than MV surgery if programs do not offer nonsternotomy options or if experience and outcomes with these patients are lacking. Minimally invasive MV repair for primary MR is now available in approximately $20 \%$ of programs in the United States, with a growing number of experienced MV programs performing robotic MV repair for primary MR with excellent outcomes and durability at increasing levels of complexity. ${ }^{3,11}$ Although not explicitly outlined in consensus recommendations, it would be reasonable to expect that comprehensive MV intervention programs should be able to offer experienced MV surgery that may include minimally invasive options. Experienced MV surgery programs are more widely accessible to the population than previously recognized. The proportion of the US population living within a Dartmouth Atlas defined hospital referral region performing 25 or more MVRRs annually is $92 \%$, with $81.7 \%$ living within a region performing more than 40 MVRRs per year. ${ }^{12}$ Although volume-outcome associations of MVRR from national data are forthcoming, data from New York state indicate that repair rates for primary MR, 1-year survival, and reoperation rates are improved when surgeons perform more than 25 cases per year. ${ }^{13}$

Apart from surgical repair and transcatheter edge-to-edge repair, several first-generation investigational devices are in clinical trials to replicate surgical repair with chordal support of primary MR and prolapsing or flail leaflets. The NeoChord (NeoChord Inc, St Louis Park, Minn) and
Harpoon (Edwards Lifesciences, Irvine, Calif) devices deliver chords via transapical access in an attempt to restore leaflet motion. Although preliminary clinical results with these devices have been mixed, both are in US clinical trials paired to surgical MV repair. ${ }^{14}$ These chordal support devices and others are helping clear the way for devices that may perform this same function, except via trans-septal access. Devices such as Chordart (Cormedic, Biel, Switzerland) and Pipeline Medical (WL Gore \& Associates, Flagstaff, Ariz) are working to refine this approach upon completing a first-in-human experience. ${ }^{15,16}$

Comprehensive MV intervention programs, while meeting consensus recommendations of volume and experience, should consider participating in clinical trials to keep abreast of pipeline technologies to preparing the MDT for future developments.

\section{Therapy for Secondary Mitral Regurgitation}

Regulatory approval for use of the clip device in prohibitive risk primary MR was based on the Endovascular Valve Edge-to-Edge Repair Study (EVEREST) II investigational device exemption trial that randomized edge-to-edge clip therapy to MV surgery for primary and secondary MR. ${ }^{4}$ Although many European patients with secondary MR have received this therapy, this has not followed suit in the United States because of lack of approval for this indication until just recently.

Two recent landmark prospective randomized clinical trials have been published studying patients with secondary MR, each with opposite results. The Cardiovascular 
Outcomes Assessment of the MitraClip Percutaneous Therapy for heart failure patients with functional mitral regurgitation $(\mathrm{COAPT})^{17}$ trial and the percutaneous repair with the MitraClip device for severe functional/secondary mitral regurgitation (MITRA-FR) ${ }^{18}$ trial both randomized secondary MR patients to receive the MitraClip and guidelinedirected medical therapy (GDMT) versus GDMT alone. Although the same device was used to treat similar populations in 2 large trials, MITRA-FR failed to meet the primary end-point revealing that treatment was no better than GDMT, whereas COAPT showed that treatment was actually superior to GDMT. ${ }^{19}$ Although much has been debated about these clinical trials and the interpretation of their results, thoughtful equipoise between GDMT, edge-to-edge, and surgery for secondary MR still exists. ${ }^{2,19}$ Although the Food and Drug Administration approved the MitraClip device for use in secondary MR in 2019, as of this writing, the Centers for Medicare and Medicaid has yet to provide a national coverage determination to guide its application into clinical practice, but this is forthcoming.

Although we know that no specific MV etiology independently affects 30-day outcome, ${ }^{20}$ MVRR for secondary MR, when analyzed in the aggregate, has not shown to improve survival or quality of life, and annuloplasty alone is associated with higher rate of MR recurrence. ${ }^{2,14,21}$ However, it is important to note that secondary MR is not a binary entity, that is, simply present or absent. Secondary MR exists as a pathoanatomic spectrum whereby leaflet motion is defined by systolic restriction, yet the degree of tethering and associated annular and ventricular dilatation may range from minimal to extensive. ${ }^{18}$ Surgeons have been repairing secondary MR at the time of CABG for many years; some patients do well, and some do not. In fact, the patient subgroup from the cardiothoracic surgical trials network ischemic MR trial that performed the best long term were those who received a successful MV repair. ${ }^{21}$ The interpretation of this finding requires more introspection of these data based on size and left ventricular volumes, because the aforementioned trial included patients with larger ventricles. Also, it is difficult to determine if the outcomes would be different if some MV repair cases received more than an annuloplasty. Although a treatise on the adjunctive therapies to MV annuloplasty, such as leaflet augmentation or papillary muscle relocation, is beyond the scope of this review, more comparative effectiveness data are required.

There has been both enthusiasm and controversy over the embrace of TMVr with the edge-to-edge clip for secondary MR. Yet, it is important to note that when De Bonis and colleagues $^{22}$ described the edge-to-edge surgical therapy, optimal outcomes were achieved only when accompanied with an annuloplasty. There have been several attempts at delivering percutaneous MV annuloplasty devices, although these are still in development or in early feasibility clinical trials such as the Cardioband (Edwards Lifesciences, Irvine,
Calif), Carillon (Cardiac Dimensions, Kirkland, Wash), or Millipede IRIS (Boston Scientific, Marlborough, Mass). ${ }^{14,23,24}$ However, TMVR appears to be emerging as the early front-runner in the ability to reliably eliminate MR and improve the outcomes of patients predominantly with secondary MR.

Several TMVR devices are in development, but few have succeeded to either global early feasibility or US pivotal trials as of this writing. The Evoque, formerly CardiAQ (Edwards Lifesciences, Irvine, Calif) is a trans-septal device with a unique leaflet anchoring mechanism that has had 14 implants ( 8 compassionate, 6 early feasibility). The 3 devices to follow are all deployed transapically. The Tiara device (Neovasc, Vancouver, Canada) has had 82 successful implants, 22 compassionate use, 27 early feasibility, and 33 in their European CE mark trial. Intrepid (Medtronic, Minneapolis, Minn) has had more than 200 successful implants with encouraging early results and safety profile, including some cases with mitral calcification, currently enrolling their US clinical trial with a nonoperative registry arm and an arm that randomizes to MV surgery. Tendyne (Abbott), with a unique apical tethering mechanism, has just more than 300 total implants with $97 \%$ procedural success and no procedural mortality having completed their early feasibility trial and currently enrolling in their US clinical trial. ${ }^{25}$ Their nonoperative arm has options for patients with and without mitral annular calcification, and their randomized arm is between Tendyne and MitraClip defined by patients in whom the participant site MDT deem to be clipable. The results from this randomized element between TMVr and TMVR for secondary MR may help provide future clarity to the question of which patients should receive clipped and which should receive replacement.

\section{Pursuit of Equipoise}

Although some patients with secondary MR may do well with edge-to-edge clip therapy, one thing that has become clear from the MITRA-FR and COAPT experience, some patients clearly do not. ${ }^{17-19}$ Likewise, some patients with ischemic secondary MR may do well with restrictive annuloplasty with or without revascularization, but some patients do not. ${ }^{19,21}$ By examining the first 100 patients who received Tendyne TMVR, it was found that some patients had excellent 1 -year survival, but some did not. ${ }^{24}$ Recently, an examination of the Tendyne experience was performed to ascertain the clinical and echocardiographic predictors of 1-year outcome after TMVR for secondary MR. ${ }^{26}$ Interestingly, and perhaps counterintuitively, there was a clear signal that patients with severe MR and larger ventricular size, actually did the best after Tendyne TMVR, whereas patients with less than severe MR, renal failure, or recent percutaneous coronary intervention had worse survival. ${ }^{25}$ This helps solidify that secondary MR is 


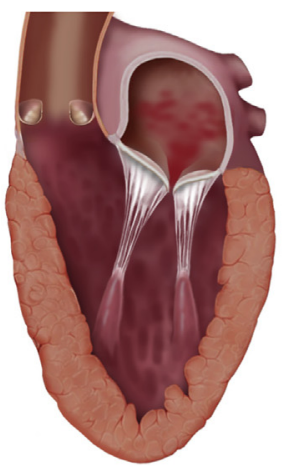

Grade I

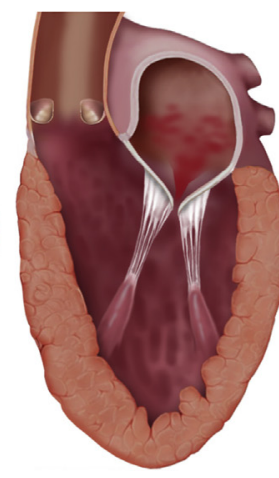

Grade II

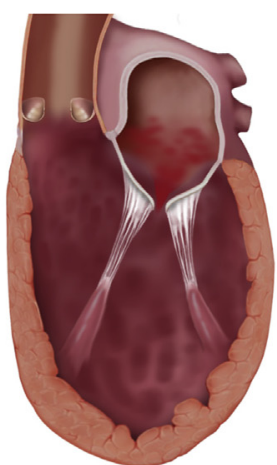

Grade III

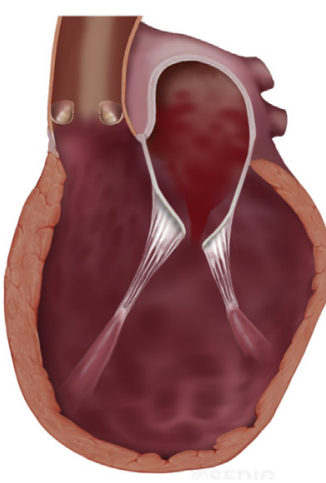

Grade IV

$\begin{array}{ccc}\text { Low } & \text { MVr } \pm \text { CABG } & \text { MVR } \pm \text { CABG } \\ \text { Risk } & & \\ \text { High } & \text { TMVr } & \text { TMVr or TMVR } \\ \text { Risk } & \text { TMV }\end{array}$

TMVR or VAD/OHTX

VAD/OHTx

FIGURE 1. Management of severe secondary mitral regurgitation by pathoanatomic severity. Grade I mild-moderate annular dilation, ejection fraction greater than $45 \%$, minimal leaflet tethering $(<5 \mathrm{~mm})$; Grade II moderate-severe annular dilation, ejection fraction $35 \%$ to $45 \%$, moderate leaflet tethering (5-10 mm); Grade III severe annular dilation, ejection fraction $25 \%$ to $35 \%$, severe leaflet tethering (>10 mm); Grade IV severe annular dilation, ejection fraction less than $25 \%$ or inferobasilar dysfunction, severe leaflet tethering ( $>10 \mathrm{~mm}) . M V r$, Mitral valve repair; $C A B G$, coronary artery bypass grafting; $T M V r$, transcatheter mitral valve repair; $M V R$, mitral valve replacement; $T M V R$, transcatheter mitral valve replacement; $V A D$, ventricular assist device; OHTX, orthotopic heart transplant.

indeed a spectrum of pathoanatomic disease that may be best served with targeted therapies along this spectrum of severity. ${ }^{19}$ For example, patients at low to intermediate risk with smaller left ventricles and less leaflet tethering will likely do well with MV annuloplasty with or without revascularization, whereas those at high or prohibitive risk may be best served with edge-to-edge clip. Patients with more leaflet tethering or larger ventricles may tend to benefit from MV replacement performed surgically in low to intermediate risk or TMVR in higher risk. Perhaps both before and after Centers for Medicare and Medicaid weighs in with their national coverage determination on edge-toedge therapy for secondary MR, the guide outlined in Figure 1 may assist the MDT assessment and treatment of these patients. ${ }^{19}$

Many patients with primary MR do extremely well with conventional or robotic surgical MV repair. Likewise, elderly patients at prohibitive risk with anatomically favorable mitral anatomy do extremely well with edge-to-edge clip with good short-term and long-term quality of life benefit. As part of a comprehensive MDT and MV intervention program, one may see patients with primary MR in the nonprohibitive high- to intermediate-risk category, such as older individuals, perhaps with comorbidities such as prior nonmitral operation, who have anatomically clipable anatomy in whom equipoise exists as to what therapy best serves the patient short term and longitudinally. This challenging management question is hoped to be answered by the percutaneous MitraClip device or surgical mitral valve repair in patients with primary mitral regurgitation who are candidates for surgery (REPAIR MR) trials that will randomize high- and intermediate-risk patients to $\mathrm{TMVr}$ with edgeto-edge clip versus surgical MV repair commencing in mid-2020.

\section{The Future Mitral Specialist}

Recent consensus recommendations on the operator and institutional requirements for transcatheter MV intervention as well as for the diagnosis and management of MR were created to serve as an inclusive guide to programs and operators (MV surgeons or interventional cardiologists) looking to provide care in an unbiased and evidence-driven manner through MDT shared decision making. ${ }^{1,2}$

\section{CONCLUSIONS}

Recent evidence and signals from active clinical trials and near term planned investigation provide a clear picture of the comprehensive mitral specialist of the future. This MV specialist will possess (1) an excellent ability to read, interpret, or even perform TEE imaging to understand the mechanism of MR and predict the anatomic solutions to provide its durable resolution; (2) mastery of MV repair techniques with a minimum of 1 year of personal followup to ensure more than $95 \%$ durable repair of primary MR with $1+$ or less MR at 1 year; (3) proficiency in minimal access or robotic MV surgery while maintaining results to deliver more than $95 \%$ primary MR repair rates and 1-year durability; (4) proficiency with performing transcatheter MV edge-to-edge clip inclusive of trans-septal access, guide catheter and clip delivery as well as deployment; (5) proficiency with performing transapical access and TMVR delivery under fluoroscopic and TEE guidance; 
and (6) interest and ability to participate in future clinical investigational options for TMVr or TMVR.

\section{Conflict of Interest Statement}

Dr Badhwar is a consultant for Abbott and serves as the co-chair of the Tendyne program executive committee (uncompensated).

\section{References}

1. Bonow RO, O'Gara PT, Adams DH, Badhwar V, Bavaria JE, Elmariah S, et al 2019 AATS/ACC/SCAI/STS expert consensus systems of care Document: operator and institutional recommendations and requirements for transcatheter mitral valve intervention: a joint report of the American Association for Thoracic Surgery, the American College of Cardiology, the Society for Cardiovascular Angiography and Interventions, and the Society of Thoracic Surgeons. J Thorac Cardiovasc Surg. 2020;160:72-92.

2. Bonow RO, O'Gara PT, Adams DH, Badhwar V, Bavaria JE, Elmariah S, et al. 2020 focused update of the 2017 expert consensus decision pathway on the management of mitral regurgitation. J Am Coll Cardiol. February 15, 2020 [Epub ahead of print].

3. Gammie JS, Chikwe J, Badhwar V, Thibault DP, Vemulapalli S, Thourani VH, et al. Isolated mitral valve surgery: the Society of Thoracic Surgeons adult cardiac surgery database analysis. Ann Thorac Surg. 2018;106:716-27.

4. Feldman T, Kar S, Elmariah S, Smart SC, Trento A, Siegel RJ, et al. Randomized comparison of percutaneous repair and surgery for mitral regurgitation: 5-year results of EVEREST II. J Am Coll Cardiol. 2015;66:2844-54.

5. Chhatriwalla AK, Vemulapalli S, Holmes DR Jr, Dai D, Li Z, Ailawadi G, et al. Institutional experience with transcatheter mitral valve repair and clinical outcomes: insights from the TVT Registry. JACC Cardiovasc Interv. 2019;12: $1342-52$.

6. Delgado V, Ajmone Marsan N, Bax JJ. Characterizing mitral regurgitation in a contemporary population: prognostic implications. Eur Heart J. 2019;40: 2203-5.

7. Nishimura RA, Otto CM, Bonow RO, Carabello BA, Erwin JP III, Fleisher LA, et al. 2017 AHA/ACC focused update of the 2014 AHA/ACC guideline for the management of patients with valvular heart disease: a report of the American College of Cardiology/American Heart Association task force on clinical practice guidelines. J Am Coll Cardiol. 2017;70:252-89.

8. Bax JJ, Debonnaire P, Lancellotti P, Ajmone Marsan N, Tops LF, Min JK, et al. Transcatheter interventions for mitral regurgitation: multimodality imaging for patient selection and procedural guidance. JACC Cardiovasc Imaging. 2019; 12:2029-48

9. Chhatriwalla AK, Vemulapalli S, Szerlip M, Kodali S, Hahn RT, Saxon JT, et al Operator experience and outcomes of transcatheter mitral valve repair in the United States. J Am Coll Cardiol. 2019;74:2955-65.

10. Badhwar V, Rankin JS, He X, Jacobs JP, Gammie JS, Furnary AP, et al. The Society of Thoracic Surgeons mitral repair/replacement composite Score: a report of the Society of Thoracic Surgeons quality measurement task force. Ann Thorac Surg. 2016;101:2265-71.

11. Coyan G, Wei LM, Althouse A, Roberts HG, Schauble D, Murashita T, et al Robotic mitral valve operations by experienced surgeons are cost-neutral and durable at 1 year. J Thorac Cardiovasc Surg. 2018;156:1040-7.

12. Vemulapalli S, Grau-Sepulveda M, Habib R, Thourani V, Bavaria J, Badhwar V. Patient and hospital characteristics of mitral valve surgery in the United States. JAMA Cardiol. October 2, 2019 [Epub ahead of print].

13. Chikwe J, Toyoda N, Anyanwu AC, Itagaki S, Egorova NN, Boateng P, et al Relation of mitral valve surgery volume to repair rate, durability, and survival. J Am Coll Cardiol. 2017;69:2397-406.

14. Prendergast BD, Baumgartner $\mathrm{H}$, Delgado V, Gérard O, Haude M, Himmelmann A, et al. Transcatheter heart valve interventions: where are we? Where are we going? Eur Heart J. 2019;40:422-40.

15. Weber A, Rucinskas K, Janusauskas V, Zakarkaite D, Zuber M, Vogel R, et al. Automated implantation of artificial mitral chords: preliminary results from the feasibility trial. Ann Thorac Surg. 2020;109:597-602.

16. Rogers JH, Ebner AA, Boyd WD, Lim S, Reardon MJ, Smith TW, et al. First-inhuman transfemoral transseptal mitral valve chordal repair. JACC Cardiovasc Interv. February 12, 2020 [Epub ahead of print].

17. Stone GW, Lindenfeld J, Abraham WT, Kar S, Lim DS, Mishell JM, et al. Transcatheter mitral-valve repair in patients with heart failure. N Engl J Med. 2018; 379:2307-18.

18. Obadia JF, Messika-Zeitoun D, Leurent G, Iung B, Bonnet G, Piriou N, et al. Percutaneous repair or medical treatment for secondary mitral regurgitation. $N$ Engl J Med. 2018;379:2297-306.

19. Badhwar V, Alkhouli M, Mack MJ, Thourani VH, Ailawadi G. A pathoanatomic approach to secondary functional mitral regurgitation: evaluating the evidence. $J$ Thorac Cardiovasc Surg. 2019;158:76-81.

20. Rankin JS, Grau-Sepulveda M, Shahian DM, Gillinov AM, Suri R, Gammie JS, et al. The impact of mitral disease etiology on operative mortality after mitral valve operations. Ann Thorac Surg. 2018;106:1406-13.

21. Goldstein D, Moskowitz AJ, Gelijns AC, Ailawadi G, Parides MK, Perrault LP, et al. Two-year outcomes of surgical treatment of severe ischemic mitral regurgitation. N Engl J Med. 2016;374:344-53.

22. De Bonis M, Lapenna E, Pozzoli A, Giacomini A, Alfieri O. Edge-to-edge surgical mitral valve repair in the era of MitraClip: what if the annuloplasty ring is missed? Curr Opin Cardiol. 2015;30:155-60.

23. Messika-Zeitoun D, Nickenig G, Latib A, Kuck KH, Baldus S, Schueler R, et al. Transcatheter mitral valve repair for functional mitral regurgitation using the Cardioband system: 1 year outcomes. Eur Heart J. 2019;40:466-72.

24. Rogers JH, Boyd WD, Smith TW, Bolling SF. Transcatheter mitral valve direct annuloplasty with the Millipede IRIS ring. Interv Cardiol Clin. 2019;8: 261-7.

25. Sorajja P, Moat N, Badhwar V, Walters D, Paone G, Bethea B, et al. Initial feasibility study of a new transcatheter mitral prosthesis: the first 100 patients. J Am Coll Cardiol. 2019;73:1250-60.

26. Badhwar V, Sorajja P, Duncan A, Thourani V, Schaefer U, Grayburn P, et al. Mitral regurgitation severity predicts one-year therapeutic benefit of Tendyne transcatheter mitral valve implantation. EuroIntervention. 2019;15: e1065-71. 